\title{
Our Results of Transcanalicular Multidiode Laser Dacryocystorhinostomy With and Without Silicon Tube Intubation
}

\author{
Sezen Akkaya
}

Department of Ophthalmology, Fatih Sultan Mehmet Trainig and Research Hospital, Istanbul, Turkey

\begin{abstract}
Introduction: To compare surgical outcomes with and without bicanalicular silicon tube intubation for the treatment of patients with primary uncomplicated nasolacrimal duct obstruction.

Methods: This retrospective study included 61 patients with uncomplicated primary nasolacrimal duct obstruction, who were divided into two groups: Group 1 underwent transcanalicular diode laser dacryocystorhinostomy surgery with bicanalicular silicon tube intubation and Group 2 underwent transcanalicular diode laser dacryocystorhinostomy surgery without bicanalicular silicon tube intubation. The mean follow-up periods were $13 \pm 0.6$ months for Group 1 and $13 \pm 0.6$ months for Group 2.

Results: Success was defined as irrigation of the lacrimal system without regurgitation and the absence of epiphora. Success rates were 80.0\% (24/30) for Group 1 and 64.5\% (20/31) for Group 2 in the first year after operation. A statistically significant difference was found between the two groups ( $p=0.03)$.

Discussion and Conclusion: Transcanalicular diode laser dacryocystorhinostomy surgery with bicanalicular silicon tube intubation was more successful than that without bicanalicular silicon tube intubation.

Keywords: Nasolacrimal duct obstruction; silicon tube intubation; transcanalicular diode laser dacryocystorhinostomy.
\end{abstract}

$\mathrm{T}$ he most common cause of lacrimal drainage system obstruction is nasolacrimal duct obstruction (NLDO), which leads to complaints such as epiphora and dacryocystitis. The obstruction can be congenital or acquired. Acquired NLDO is mostly seen in patients aged $>40$ years and its incidence rapidly increases in those aged $>60$ years ${ }^{[1]}$. Known risk factors are advanced age, white race, female sex (4-5-fold), and low socioeconomic status ${ }^{[2-4]}$. Primary acquired NLDO is mostly idiopathic, whereas secondary acquired NLDO may be due to trauma, infection, inflammation, neoplasm, or mechanical factors ${ }^{[1]}$.
The goal in the treatment of NLDO is to maintain the drainage of tears. Medical treatment is performed in acute cases. Definitive treatment in cases wherein medical treatment is inadequate and in cases of chronic dacryocystitis is surgery ${ }^{[5]}$. The primary option in surgery is dacryocystorhinostomy (DSR), namely creating a new permanent pathway between the lacrimal sac and the nasal mucosa. The first known external DSR operation was described by Toti in $1904{ }^{[6]}$. Although treatment via external surgical approach is still the gold standard with the highest success rate, the latest development in DSR is the endocanalicular

Correspondence (iletişim): Sezen Akkaya, M.D. Department of Ophthalmology, Fatih Sultan Mehmet Trainig and Research Hospital, Istanbul, Turkey

Phone (Telefon): +90 2165783000 E-mail (E-posta): drsezenakkaya@gmail.com

Submitted Date (Başvuru Tarihi): 08.02.2018 Accepted Date (Kabul Tarihi): 16.04.2018

Copyright 2018 Haydarpaşa Numune Medical Journal

This is an open access article under the CC BY-NC license (http://creativecommons.org/licenses/by-nc/4.0/). 
or transcanalicular diode laser approach.

Laser-assisted DSR application was introduced by Massaro et al. in 1990 with cadaver studies using a blue-green argon laser. Eventually, Reifler used potassium titanyl phosphate in 1993, then holmium YAG, $\mathrm{CO}_{2}, \mathrm{Nd}: \mathrm{YAG}$, and erbium lasers have been also used ${ }^{[7-9]}$. Subsequent studies have shown delayed postoperative wound healing and prolonged inflammation in laser-treated tissues in $\mathrm{CO}_{2}$ laser and $\mathrm{Nd}$ :YAG laser applications ${ }^{[10]}$. Diode laser $(980 \mathrm{~nm})$ is the most preferred method in terms of both low tissue damage and adequacy of the osteotomy to be created. The first endoscopic DSR surgery with diode laser was implemented by Eloy et al. in 2000 and maintained its up-to-dateness afterward ${ }^{[11]}$.

Some investigators prefer silicone tube intubation in all cases of NLDO surgery ${ }^{[12]}$, whereas others prefer silicone tube intubation only for definite indications (canalicular injury, lacrimal sac inflammation, secondary surgery, small, contralateral sacs, etc.) ${ }^{[13]}$.

The aim of this retrospective study was to compare the surgical outcomes of the transcanal diode laser DSR (TDLDSR) surgery with and without bicanalicular silicone tube intubation in the treatment of 61 patients with primary uncomplicated NLDO.

\section{Materials and Methods}

In this study, 61 eyes of 61 patients with primary NLDO who underwent TDL-DSR at our clinic between 2015 and 2017 were included. The study was carried out in accordance with the principles of the Helsinki Declaration. Informed consent form was obtained from all patients. Patients were divided into two groups and retrospectively examined. Group 1 consisted of 30 patients who underwent TDL-DSR with bicanalicular silicone tube intubation and Group 2 consisted of 31 patients who underwent TDL-DSR without bicanalicular silicone tube intubation. After completion of the ocular examination, NLDO was preoperatively confirmed with lacrimal irrigation, and presence of lacrimal sac was observed with direct dacryocystography with lipiodol injection.

Inclusion criteria of the study were as follows: (i) no history of nasolacrimal duct surgery; (ii) absence of canalicular obstruction; (iii) no evidence of traumatic injury to the eye or nasal region; (iv) no accompanying nasal pathology such as septum deviation, concha bullosa, nasal polyposis, and atrophic rhinitis; $(v)$ absence of active infection of dacryocystitis; and (vi) absence of dry eye and ptosis of the lower lid. All surgeries were performed under local anesthesia. In- tramuscular benzodiazepine was administered to the patient. Prior to surgery, topical anesthetic drops $(0.4 \%$ oxybutuproxine hydrochloride) were instilled into the conjunctiva and cornea. Then, intranasal and lateral nasal anesthesia was induced with a mixture of epinephrine hydrochloride and lidocaine solution.

Local anesthesia was induced in the region of the "infraorbital nerve" and "medial canthus" with the injection of a mixture of epinephrine hydrochloride and lidocaine solution (Jetokain ${ }^{\circledR}$ injection, ADEKA,Turkey). After dilation with punctum dilators, the flexible fiber DSR laser probe was advanced through the canal to the wall of the lacrimal sac. During this insertion, the probe coming into contact with a hard surface indicated that we were inside the lacrimal bone. Simultaneously, the endoscope and aspiration probe inserted through the nasal cavity allowed the visualization of the red light reflex at the end of the fiber on the nasal wall opposite the middle conical surface. In this way, the target tissue to be exposed to laser was precisely determined.

The parameters of the diode laser (INTERmedic ${ }^{T \mathrm{M}}$ diode $\mathrm{S} 30$ OFT $980 \mathrm{~nm}$ ) were set as $500 \mathrm{~ms}$ pulse mode and $10 \mathrm{~W}$ to avoid unnecessary heating of the tissue. After reaching the nasal cavity, the osteotomy was extended to $1 \times 1 \mathrm{~cm}$, down, up, and to both sides. An aspirator was used to protect the middle concha and septum and aspirate the bleeding. The laser application was adjusted to $35-55$ shots at $10 \mathrm{~W}$. At the end of the operation, the laser probe was removed and the opening was checked by lacrimal duct lavage with saline.

In Group 1, bicanalicular silicone tube intubation was additionally performed. Silicone extensions of the tube were spliced and then released in the nasal cavity. Furacin (nitrofurazone $0.2 \%$ ) impregnated pad was placed in the nasal cavity for hemostatic control. On the first postoperative day, the pad was removed. After surgery, antibiotics and steroid eye drops, nasal steroid sprays, and nasal saline solutions were recommended to be used four times daily for 2 weeks. In addition, oral antibiotics were recommended for 1 week.

Patients were controlled postoperatively at 1 day, 1 week, 1 month, 3 month, and then at intervals of 3 months. Care was taken to wait 6 months to remove the silicone tubes. In 4 patients, the tube was removed between 3 and 6 months on the request of the patient. During control visits, the patency of the lacrimal drainage system was checked. The absence of symptomatic epiphora and smooth passage of the nasolacrimal lavage fluid were defined as success. The 
mean follow-up period was $13 \pm 0.6$ months for Group 1 and $13 \pm 0.4$ months for Group 2.

\section{Statistical Analysis}

Statistical analyses were performed using SPSS 14.0 (Statistical Package for Social Sciences, SPSS Inc., Chicago, IL). Normal distribution of the variables in consideration was first assessed using the Shapiro-Wilk test. Data were presented as mean \pm standard deviation for continuous variables and categorical data were expressed as the number of cases. Independent sample test was used to compare the means of Group 1 to Group 2. Differences between the groups were analyzed using chi-square test.

\section{Results}

The study population of 61 patients was divided into Group 1 (16 females and 14 males; mean age, 55.36 \pm 33.21 years) and Group 2 (16 females and 15 males; mean age, $52.18 \pm 25.21$ years). There was no statistically significant difference between the groups in terms of age and sex distribution ( $p>0.05$ ). Surgical success rates achieved in patients as evaluated at 1 year postoperatively were $80.0 \%$ (24/30) for Group 1 and 64.5\% (20/31) for Group 2. A statistically significant difference was observed between the groups in terms of surgical success rates $(p=0.03)$.

The mean operative times for Groups 1 and 2 were $45.8 \pm 10.2$ and $25.2 \pm 5.3$ minutes, respectively. Surgery lasted longer in Group 1 due to the additionally applied tube intubation with a statistically significant intergroup difference $(p=0.02)$. The mean total laser energy used in Groups 1 and 2 were $627 \pm 68.3$ and $638 \pm 71.4 \mathrm{~J}$, respectively. There was no statistically significant difference between the groups in terms of the total mean laser energy used ( $p>0.05)$. Characteristics of Groups 1 and 2 are shown in Table 1.

When the success rates calculated at 1, 3, and 6 months and at 1 year postoperatively were evaluated, higher operative success rates were achieved at 1, 3, and 6 months in Group 1, without any statistically significant difference between the groups. The operative success rate in Group 2 decreased in the first postoperative year, and the success rates between the two groups for the first year were statistically significant $(p=0.03$ ). The success rates at postoperative controls are shown in Table 2.

Granuloma was detected during endoscopic examinations in 2 patients in Group 1. These granulomas were removed by the otolaryngologist using endoscopic procedures. Because of the mucosal scarring around the osteotomized area, outcomes in 4 cases were evaluated as failure. There were no other complications such as erosion of the punc-
Table 1. Characteristic features of Groups 1 and 2

\begin{tabular}{lccc}
\hline & Group 1 (30) & Group 2 (31) & p \\
\hline Age & $55.36 \pm 33.21$ & $52.18 \pm 25.21$ & 0.16 \\
Sex & & & \\
$\quad$ Male & 14 & 15 & \\
$\quad$ Female & 16 & 16 & 0.32 \\
Success rate at & $(24 / 30) \% 80.0$ & $(20 / 31) \% 64.5$ & $0.03^{*}$ \\
postoperative 1 year & & & \\
Mean operative time (min) & $45.8 \pm 10.2$ & $25.2 \pm 5.3$ & $0.02^{*}$ \\
Mean total laser energy (Joule) & $627 \pm 68.3$ & $638 \pm 71.4$ & 0.56 \\
\hline *(p $\leq 0.05)$. & & &
\end{tabular}

Table 2. Success rates at postoperative controls

\begin{tabular}{lccc}
\hline & Group 1 (30) & Group 2 (31) & p \\
\hline 1 month (\%) & 96.6 & 93.5 & 0.65 \\
3 month (\%) & 90.0 & 87.1 & 0.53 \\
6 month (\%) & 83.3 & 80.6 & 0.48 \\
1 year (\%) & 80.0 & 64.5 & $0.03^{*}$ \\
\hline
\end{tabular}

${ }^{*}(p \leq 0.05)$.

tum, skin fistula, and removal of the tubes. In Group 2, endoscopic examinations revealed secondary ostium scar formation in 8 patients and epiphora persisted in 3 patients. Reoperation was performed between 3 and 6 months in 2 patients. One patient in Group 2 developed dacryocystitis at postoperative 1 month.

\section{Discussion}

During the first 6 months after TDL-DSR, success rates were similar between the two groups. After 6 months, the silicone tube was not applied, the osteotomy area was closed, and the success rate gradually decreased. In the first year, the success rate was higher in the group treated with silicone tube intubation. Because silicone tube prevented further closure of the opening.

TDL-DSR is a minimally invasive surgical procedure and has the great advantage of accessing the operation area through anatomic routes. It minimizes trauma to the surrounding tissue, protects the medial canthal ligament, prevents unnecessary surgical skin scarring, and allows ablation, dissection, and removal of the tissue. In addition, TDL-DSR causes minimal pain and minimal nasal bleeding. It is also possible to intervene simultaneously with nasal pathologies. Compared with the conventional dacryocystorhinostomy, it is easier and quicker to perform. However, TDL-DSR has many disadvantages: it requires training in the use of laser and endoscopy, it has a lower success rate than the conventional external DSR method, and materials 
used are more expensive ${ }^{[14]}$.

Silicone tube intubation during DSR is used to prevent occlusion of the lacrimal passage and to provide epithelization. Silicone is an inert substance, does not harm the conjunctiva, and can be well tolerated in the canaliculi. As noted above, silicone tube intubation is recommended for patients with coexisting canalicular diseases, narrowed or injured lacrimal sacs, and persistent congenital NLDO. Aytıntap et al. assessed the relationship between failure and age in TDL-DSR cases where they applied silicone tubing and found a relationship between failure and age. While the rate of failure was higher in younger patients, the rate of success increased with age ${ }^{[15]}$.

There are few studies in the literature regarding the use and non-use of silicone tube intubation in DSR. Although some studies have reported that silicone tube use is not a statistically significant advantage in DSR $[16,17]$, other studies recommend tube intubation in DSR ${ }^{[18]}$.

Feng et al. ${ }^{[17]}$ investigated 9 studies involving 514 cases in their meta-analysis and concluded that additional silicone tube intubation in dacryocystorhinostomy did not provide any additional benefit.

One of the most important factors for failure is narrow $(<1$ $\mathrm{cm}$ ) osteotomy opening. In such cases, the risk of recurrence increases. In our study, osteotomy opening was $>1 \times$ $1 \mathrm{~cm}$ in all patients. However, it has been reported that specific wound healing and tissue response affect the patency of the passage independently of the osteotomy opening size ${ }^{[14]}$. The success rate in this study was $80.0 \%(24 / 30)$ in the TDL-DSR group and $64.5 \%$ (20/31) in the other DSR group without application of silicone tube, with a statistically significant difference between the groups ( $p \leq 0.05)$.

Success rates have been reported to range between $80 \%$ and $99 \%$ in external DSR cases and between $58 \%$ and $97 \%$ in endoscopic procedures ${ }^{[19,20]}$. Mitomycin C administration to the osteotomy region is among the measures taken to prevent restenosis in the constructed osteotomy opening. Kar et al. ${ }^{[21]}$ reported higher success rates for TDL-DSR procedures in which they applied mitomycin $C$ to the osteotomy site. Antifibrotic agent was not used in our study.

There were 17 failures in our study: 6 failures in Group 1 and 11 failures in Group 2. In 2 failures in Group 1, granulomatous tissue formation occurred. In Group 2, dacryocystitis was observed in 1 patient. In addition, scars on the ostium were observed in 4 patients in Group 1 and in 11 patients in Group 2 during endoscopic examinations.

Rebeiz et al. ${ }^{[22]}$ recommended 4-6 weeks for the duration of silicone tube intubation. To prevent granuloma forma- tion, Kong et al. ${ }^{[23]}$ suggested that the tubes should not be removed before 8 weeks. Häusler and Caversaccio reported that tubes are well tolerated by patients and that the nasolacrimal duct remains open for months or even years. In their study, the tubes remained in place for an average of 9 months ${ }^{[24]}$. In the current study, silicone tubes were removed after at least 6 months after surgery, except in 4 patients. The bicanalicular tubes in the lacrimal ducts were well tolerated by all patients without any significant problems. In the study, during silicon tube placement, care was taken not to traumatize the tissues, but to tie the ends of the silicone tube with an ideal tension.

In this study, we concluded that the success rates of the two TDL-DSR groups with and without silicone tube intubation were different. According to the results of this study, bicanalicular silicone tube intubation should be performed with TDL-DSR in patients with primary NLDO.

Peer-review: Externally peer-reviewed.

Conflict of Interest: None declared.

Financial Disclosure: The authors declared that this study received no financial support.

\section{References}

1. Woog J. The incidence of symptomatic acquired lacrimal outflow obstruction among residents of Olmsted County, Minnesota, 1976-2000 (an American Ophthalmological Society thesis). Trans Am Ophthalmol Soc 2007;105:649-66.

2. Olcina LI. Dacriocistitis. Annals d'Oftalmologia 2007;15:192-8.

3. Jonathan J, Yanoff M, Duker SJ. The lacrimal drainage system. In: Yanoff M, Duker JS, editors. Ophthalmology. 2nd ed. St. Lois: Mosby; 2004. p. 171-8.

4. Miranda Anta S, Blanco Mateos G, Valverde Collar C. Dacryocystorhinostomy in adolescents and young adults [Article in Turkish]. Arch Soc Esp Oftalmol 2011;86:243-6. [CrossRef]

5. Lee S, Yen MT. Laser-assisted dacryocystorhinostomy: a viable treatment option? Curr Opin Ophthalmol 2011;22:413-8.

6. Toti A. Nuovo metodo conservatore di cura radicale delle suporazioni croniche del sacco lacrimale. Clin Med Firenze 1904;10:385-9.

7. Massaro BM, Gonnering RS, Harris GJ. Endonasal laser dacryocystorhinostomy. A new approach to nasolacrimal duct obstruction. Arch Ophthalmol 1990;108:1172-6. [CrossRef]

8. Gonnering RS, Lyon DB, Fisher JC. Endoscopic laser-assisted lacrimal surgery. Am J Ophthalmol 1991;111:152-7. [CrossRef]

9. Woog JJ, Metson R, Puliafito CA. Holmium: YAG endonasal laser dacryocystorhinostomy. Am J Ophthalmol 1993;116:110. [CrossRef]

10. Luomanen M, Rauhamaa-Mäkinen $R$, Meurman JH, Kosloff $T$, Tiitta O. Healing of rat mouth mucosa after irradiation with $\mathrm{CO} 2, \mathrm{Nd}: \mathrm{YAG}$, and CO2-Nd:YAG combination lasers. Scand J 
Dent Res 1994;102:223-8. [CrossRef]

11. Eloy P, Trussart C, Jouzdani E, Collet S, Rombaux P, Bertrand B. Transcanalicular diode laser assisted dacryocystorhinostomy. Acta Otorhinolaryngol Belg 2000;54:157-63.

12. Al-Asadi SZ, Al-Abbasi AM. Efficacy of diode laser transcanalicular dacryocystorhinostomy in acquired nasolacrimal duct obstruction. Gomal Journal of Medical Sciences, 2011;9:1524.

13. Ari S, Kürşat Cingü A, Sahin A, Gün R, Kiniş V, Caça I. Outcomes of revision external dacryocystorhinostomy and nasal intubation by bicanalicular silicone tubing under endonasal endoscopic guidance. Int J Ophthalmol 2012;5:238-41.

14. Bardak H, Ekim MM, Daldal H. Endoscopic Transcanalicular Laser Dacryocystorhinostomy in Primary Nasolacrimal Duct Obstruction [Article in Turkish]. Turkiye Klinikleri J Ophthalmol 2015;24:157-62. [CrossRef]

15. Ayintap E, Buttanri IB, Sadigov F, Serin D, Ozsutcu M, Umurhan Akkan JC, et al. Analysis of age as a possible prognostic factor for transcanalicular multidiode laser dacryocystorhinostomy. J Ophthalmol 2014;2014:913047. [CrossRef]

16. Al-Qahtani AS. Primary endoscopic dacryocystorhinostomy with or without silicone tubing: a prospective randomized study. Am J Rhinol Allergy 2012;26:332-4. [CrossRef]

17. Feng YF, Cai JQ, Zhang JY, Han XH. A meta-analysis of primary dacryocystorhinostomy with and without silicone intubation.
Can J Ophthalmol 2011;46:521-7. [CrossRef]

18. Yildirim Y, Kar T, Topal T, Cesmeci E, Kaya A, Colakoglu K, et al. Comparison of Transcanalicular Multidiode Laser Dacryocystorhinostomy with and without Silicon Tube Intubation. J Ophthalmol. 2016; 2016:6719529. [CrossRef]

19. Pal VK, Agrawal A, Suman S, Pratap VB. Transcanalicular endoscope combined laser-assisted dacryocystorhinostomy. Oman J Ophthalmol 2013;6:99-102. [CrossRef]

20. Horix D, Struck HG. Long term patency rate of the external dacryocystorhinostomy. A retrospective study in the years 1991-2000 at the University Eye Hospital in Halle [Article in German]. Ophthalmologe 2004;101:268-77. [CrossRef]

21. Kar T, Yildirim Y, Topal T, Çolakoğlu K, Ünal MH. Efficacy of adjunctive mitomycin $C$ in transcanalicular diode laser dacryocystorhinostomy in different age groups. Eur J Ophthalmol 2016;26:1-5. [CrossRef]

22. Rebeiz EE, Shapshay SM, Bowlds JH, Pankratov MM. Anatomic guidelines for dacryocystorhinostomy. Laryngoscope 1992;102:1181-4. [CrossRef]

23. Kong YT, Kim TI, Kong BW. A report of 131 cases of endoscopic laser lacrimal surgery. Ophthalmology 1994;101:1793-800.

24. Häusler R, Caversaccio M. Microsurgical endonasal dacryocystorhinostomy with long-term insertion of bicanalicular silicone tubes. Arch Otolaryngol Head Neck Surg 1998;124:18891. [CrossRef] 